DOI: $10.20472 / E F C .2020 .014 .008$

\author{
BOŽENA KADEŘÁBKOVÁ \\ University of Economics, Prague, Czech Republic \\ EMILIE JAŠOVÁ \\ Faculty of Social Sciences, Charles University in Prague, Czech Republic
}

\title{
PHILLIPS CURVE DURING THE ECONOMIC CYCLE IN THE CZECH REPUBLIC AND POLAND IN THE YEARS 2000 TO 2016
}

\begin{abstract}
:
The aim of the research paper is to analyze the development of the Phillips curve and the NAIRU, including the unemployment gaps in the Czech Republic and Poland in individual phases of the economic cycle, when using empirical analysis. According to the analysis, the resulting average value of the negative slope of the PC for the whole observed period in the Czech Republic is -0.19 and in Poland -0.09 , which in both countries indicates a very weak intensity of substitutability of the household consumption deflator by unemployment. The resulting long-term NAIRU for the entire period we are monitoring was $6.70 \%$ in the Czech Republic and $12.50 \%$ in Poland. NAIRU values are affected by unemployment benefits, in the Czech Republic also by the growth of the minimum wage and in Poland by the growth of import prices, including the growth of oil prices. Research also shows expected inflation in both countries.
\end{abstract}

\section{Keywords:}

Unemployment rate by gender, age and education, Phillips curve, long-term NAIRU, phase of the economic cycle, inflation expectations

JEL Classification: E24, E32, E37 


\section{Introduction}

This research paper examines the relationship between unemployment and inflation through the theoretical concept of Phillips curve (PC) and Non-Accelerating inflation rate of unemployment (NAIRU) in individual phases of the economic cycle in the Czech Republic and Poland. The concept of PC and NAIRU was developed in accordance with the facts in the past, and despite the decline in interest in the 1970s, it has been subject of interest since the 1990s for its applicability to structural reforms, market efficiency improvment, etc.

The following section provides a historical excursion into the development of PC and NAIRU concepts in international and domestic research. The next part is focused on economic policy measures to support employment and the reasons for the development of PC and NAIRU. The fourth part describes the data sources and methods of analysis used. The fifth part presents an overview of econometric results and the last part is a summary of findings from the analysis.

\section{Overview of the conceptual framework of PC and NAIRU}

According to Humphrey (1985), at least 10 authors have dealt with substitution between unemployment and indicators of inflation over the 240 years before Phillips and can be divided into three groups. The first group consists of authors assuming a relationship between price inflation and unemployment. This group includes Law, Hume (1752), Thornton (1802), Attwood (1816), Mill (1833) and Brown (1955). In the second group, the authors present PC concepts based on wage inflation such as Tinbergen (1951, 1959), Klein and Goldberger (1955). The third group consists of authors who brought the first statistical analysis of PC (Fisher, 1926) and a graphical presentation of PC (Sultan). Phillips (1958) hypothesized that wage inflation could be explained by the rate of unemployment and the rate of its change. To date, these concepts have had a number of successors: Samuelson and Solow (1960), Friedman (1968), Phelps (1967), Akerlof, Dickens and Perry (1996), Tobin (1997), Ball and Moffitt (2001), Fabiani and Mestre (2001) and others.

Tobin (1997) is considered to be the author of the NAIRU concept, according to which it is the result of a macroeconomic balance of pressures on inflationary growth from markets with excess demand with pressures on inflationary decline from markets with oversupply. Gordon (1996) considers the NAIRU to be an unemployment rate that is consistent with a constant rate of inflation. McAdam and McMorrow (1999) state that a number of structural factors will affect long-term NAIRU. NAIRU is not tied to a specific concept of PC and is not a invariant quantity.

World and domestic research from 2013 to 2016 in this topic explain the reasons for changes in the behavior of substitution during and after the global financial and economic recession. For example, Gordon (2013) uses the effect of short-term unemployment (up to 26 weeks) on inflation before long-term unemployment to analyze model simulations based on analysis of US data. According to Coibion and Gorodnichenko (2015), replacing corporate expectations with household expectations eliminates the absence of disinflation. Ma (2014) demonstrates in the US data until the end of Q3 2013 a reduction in the rate of inflation in all recessions and its growth in expansions. According to Watson (2014), the reason for the smaller decline in US inflation between 2007 and 2013 than between 1979 and 1985 is the change in inflation persistence, as inflation is more anchored than in the 1980s. Rusticelli (2014) analyzes data from OECD countries and the European Union (EU) until the end of 2012 and concludes that the $\mathrm{PC}$ is flatter due to rising levels and rising unemployment on the growth of nominal wage rigidity and many other causes (migration, inflation expectations, deepening 
integration in the EU, pressures in global markets). Marjanovic, Maksimovic and Stanisic (2015) found out the presence of hysteresis effects in eight countries (Bulgaria, Hungary, Poland, Romania, Slovenia, Slovakia, Croatia and the Czech Republic) in the transformation between 2000 and 2012.

Authors in the Czech Republic such as Andrle, Brůha and Solmaz (2013) state that the frequency of the economic cycle and the relationship between output and core inflation in the period from Q1 1995 to Q1 2013 is stable. The strong relationship between output and inflation demonstrates the great importance of demand shocks for the euro area economic cycle. Baxa, Plašil and Vašíček (2013) oppose this on data from the USA and the G7 countries in the period from the 1st quarter of 1995 to the 2nd quarter of 2013, when they found that the relationship between economic activity and inflation is relatively robust only when using more complex forms of measurement. Baxa, Plašil and Vašíček (2013) oppose this, when they use data from the USA and the G7 countries in the period from the Q1 1995 to the Q2 2013, when they found that the relationship between economic activity and inflation is relatively strong only when using more complex forms of measurement. In the last decade, however, the use of all methods across all countries has weakened this relationship (socalled flattening of the PC), which may be due to structural changes in the economy and monetary policy. The authors also found that foreign factors play a major role in inflation in the large G7 countries as well. Reitz and Slopek (2013) claim that it weakens the relationship between inflation and unemployment, which reduces its suitability for making inflation forecasts.

\section{Economic policy measures to support employment and impacts on the development of PC and NAIRU}

Cohen (1969) argues that the use of workforce support programs (on-the-job training, study, etc.) leads to the need to correct PC concepts, labor productivity analysis, and employment measurement. The growth in demand for labor is leading to a movement along the PC, which is resulting in lower unemployment and wage growth. An alternative is to shift the PC curve to the left. Programs cause the PC to shift to the left, for example, by shortening the time between jobs (growth of information in the market will reduce the number of unemployed at the current wage rate), increase the number of people in scarce occupations and train the long-term unemployed.

Baily et al. (1977) considers the policy of direct job creation and selective wage support as an opportunity to gain employment for workers who are normally unemployed. This means a reduction in the inflationary consequence of higher employment rates in the short term.

According to Wallich (1978), measures that would simultaneously reduce unemployment and inflation are in tax-oriented policies (the family of tax-oriented incomes policies - TIP).

Katz et al. (1999) analyzes the unusual combination of low unemployment and low inflation in the 1990s. If this development is the result of labor market movements, it may permanently reduce the NAIRU. If the development is caused outside the labor market, it may be a temporary shock that will allow temporarily low unemployment and inflation (falling energy prices, falling employers' spending on health and social security, cheaper IT, etc.).

In the application part of the paper, we modify the one-equation model with a categorical variable - the phase of the cycle. It localizes the unemployment rate throughout the time period by gender, age and education for several time periods, in which the inclination of the PC, its character and intensity change with the phase of the economic cycle. Other categorical variables are gender, age, education and V4 countries, with the help of which we 
will gain a comprehensive insight into the development of PC and NAIRU in selected countries.

\section{Description of used data sources and methods of analysis}

PC slope (character and intensity) and NAIRU values, including the unemployment gap, were examined using the Total unemployment rate indicator (aged 15-64), by sex, age and educational attainment level $-\%$ (hereinafter unemployment rate by sex, age and education). All sub-combinations of this labor market indicator were taken from Eurostat (Eurostat, 2017). Two countries V4 (the Czech Republic and Poland) were selected for joint research due to the continuing similarity of economic developments. This is due to administrative measures in the transition from a centrally planned to a market economy, a similar structure of economies and a similar degree of openness and the associated high susceptibility to continuous change. Unlike previous research, we will now focus on analyzing the combinations created by breaking down aggregate indicators of the unemployment rate by gender, age and education.

Data from labor market related indicators were also drawn from Eurostat (Eurostat, 2017). Specifically, the indicators Employment incentives (average annual status) and Start-up incentives (average annual status) proved to be statistically significant. The indicators household consumption deflator, consumer price index, GDP at constant prices, import prices and Brent crude oil prices (in all cases year-on-year changes in\%) were published on the OECD website (Global Economic Outlook, 2017).

In addition to these numerical variables, time series of these categorical variables were also compiled: gender, age, education, and cycle phase. The categorical variable phase of the cycle, which was to capture cyclical fluctuations in economic development in the time series of unemployment rates, was created according to the statistically published development of GDP at constant prices. The whole time period was then divided into five periods in all countries. Specifically, it is the period of the first boom, the first recession, the second boom, the second recession and the third boom.

The time series used have a quarterly frequency and provide information for the period from Q1 2000 to Q4 2016. Exceptions are the indicators employment support and start-up incentives, which are available only from Q1 2004. From the original time series of numerical variables were the analysis calculated year-on-year changes in\% (employment support, startup incentives, GDP at constant prices, import prices and the price of Brent crude oil) and in pp (household consumption deflator), which better capture labor market dynamics.

All used timelines were tested by the ADF test (Eviews, 2013), which confirmed their stationarity. Also, all series (with the exception of employment by sex, age and education, which were also published after seasonal adjustment) were seasonally adjusted using the Census X12 method (Eviews, 2013). We use linear regression to estimate the slope of the $\mathrm{PC}$, the nature and intensity of the substitutability of the household consumption deflator by unemployment. The slope of the PC for unemployment rates in a detailed breakdown from different perspectives is then extracted by defining categorical variables in interaction with the unemployment rate by gender, age and education. In this way we can find out the tendency of PC, its character, intensity and confirm or refute the substitutability of the deflator of household consumption by unemployment for each V4 country according to gender, age, education but also according to the phase of the economic cycle together.

An adjusted $R^{2}$ is applied for choosing the most suitable model to approximate the analyzed data. The Jarque Berus test (Eviews, 2013) is used to test the residual normality. To test the 
autocorrelation of residues, Breusch-Godfrey's test is applied (Eviews, 2013). For testing the heteroskedasticity of the residuals, the Wald test (Eviews, 2013) is used. To measure the viability of multi-collinearity, the Variable Inflation Factor (Eviews, 2013) is used in the analysis. The failure of normality of residuals tests due to fluctuations in the development of some segments of the explained variable and the calculated year-on-year changes in the case of a large amount of observations allows assuming the validity of a central limit theorem that states that the $t$ - tests are asymptotically valid. The reason for the presence of heteroskedasticity in the models (except for the explained long-term unemployment variable) is the same as for the abnormality. Thus, the point estimates will not be influenced or deflected.

The slope of the PC, its character and intensity are obtained by modifying the standard model for inflation according to J. S. Sekhon (1999) by categorical variables. The inflation equation is then estimated using the least squares method. The value of the regression coefficient of the unemployment rate by sex, age and education then indicates the nature and intensity of the PC slope. In the text, the negative sign is an estimate of the slope of the PC in accordance with the economic theory of substitution and empirical analyzes. This result supports Gordon (2013) in rejecting PC failures. We consider the reduction of the value of the negative slope of the PC between the phases of the economic cycle to be its flattening, which we explain with the findings from the latest international and domestic research. In the case of a positive sign, we speak of the failure of substitution between the consumption deflator and the unemployment rate by sex, age and education. This conclusion does not confirm the legitimacy of the arguments of the proponents of the usability of the PC against the critics and supports the inclination towards the NKPC. If the categorical variable in the interaction with the unemployment rate by sex, age and education is not statistically significant in the model, we speak of failure to prove substitution. According to the experience of the latest research, various ways of modifying commonly used methods can be applied in order to improve PC estimates. Regression coefficients in the range from 0.01 to 0.20 in our analysis indicate a very weak substitutability of the household consumption deflator by unemployment, resp. very flat PC. Regression coefficients in the range from 0.21 to 0.40 indicate weak substitutability, resp. about a flat PC. Values in the range from 0.41 to 0.60 indicate the mean substitutability, resp. medium PC slope. The regression coefficient in the range from 0.61 to 0.80 indicates strong substitutability, resp. a steep PC and an interval from 0.81 to 1.00 locates a very strong substitutability, resp. very steep PC.

NAIRU values are estimated by applying an HP filter in accordance with the recommendations of the latest world and domestic research in terms of a combination of alternative tools. The unemployment gap, which characterizes the development of the economic cycle on the labor market and its position in it, is then obtained by subtracting the NAIRU calculated in this way from the actual unemployment rate.

\section{Overview of results from empirical testing of the development of PC slope and NAIRU values in the Czech Republic and Poland}

The substitution of the household consumption deflator by the unemployment rate by sex, age and education in the Czech Republic and Poland will be shown by the inclination of the PC, its character and intensity, and NAIRU values in individual phases of the economic cycle. The evolution of the PC slope is obtained by regression analysis, which is based on the extended One-Equation Model (Gordon's “Triangle" Model) with categorical variables dividing the entire time period into several time periods. NAIRU values were obtained by applying an 
HP filter. Economic policy measures are based on their general definition in Part 2. Labor market indicators for selected countries are in the structure in Part 4 of this paper.

\section{a. Analysis of the development of PC slope and NAIRU values in the Czech Republic}

The analysis of the first boom (Q1 2001 to Q3 2008) typically shows a negative slope of the PC of 0.31 , which indicates a weak substitutability of inflation according to the deflator of household consumption by unemployment by sex, age and education. In the case of the data for men, the negative slope of PC was 0.35 and in the case of data for women 0.27 , with a weak intensity of substitutability in both cases. The average value of the NAIRU during the first boom was $7.32 \%$. By comparing the NAIRU estimate with the actual unemployment rate, a positive unemployment gap of $-0.12 \mathrm{pp}$ was identified in this period, which is in line with the phase of the economic cycle indicated by published GDP at constant prices. The location of the estimated PC (see Graph 1) was mainly the result of a year-on-year decrease in employment support (by 20.3\%) and a start-up (by 13.6\%) by the government. However, Brent oil prices also increased year-on-year in this period (by $17.3 \%$ ).

In the following period - the first recession ( $4 Q 2008$ to $4 Q 2009)$ there was a slight increase in the negative tendency of PC compared to the first phase of the boom to 0.39 , with the fact that we continue to assess the intensity of substitution as weak. In the case of the data for men, the increased slope value was -0.41 , which already represents a mediumintensity substitution. In the case of data for women, increasing the PC slope to -0.36 means confirming the assessment of the intensity of substitution from the previous phase as weak. The average statistically confirmed value of NAIRU during the first recession was $6.40 \%$. Subtracting the statistically confirmed NAIRU estimate from the actual unemployment rate, the average positive unemployment gap was $-0.10 \mathrm{pp}$. As this was the result of developments in the first two quarters and the remaining three quarters already showed a negative unemployment gap, its consistency with the published phase of the recession by GDP can also be stated here. The shift in the estimated PC to the left compared to the first phase of the boom (see Graph 1) was due, among other things, to a year-on-year decline in the minimum wage in this period (by $2.12 \%$ ). Import prices (by $1.5 \%$ ) and the price of Brent crude oil (by $22.3 \%$ ) also decreased year-on-year.

In the next period - the second boom (Q1 2010 to Q1 2012) there has been a violation of the theoretically expected substitution between household consumption deflator and all combinations of unemployment by gender, age and education. The statistically significant positive slope for this whole phase was only 0.06 . In the case of data for men, it was +0.05 . In the case of data for women, the positive slope of PC was 0.06 and we evaluate PC as very flat. The average statistically confirmed NAIRU value in the second boom period was $6.70 \%$. By comparing the statistically confirmed NAIRU estimate and the actual unemployment rate, we obtained a negative unemployment gap in this period of an average of $+0.40 \mathrm{pp}$. The legitimacy to evaluate the result obtained in this way stems from the development in this period, which indicates a gradual transition of the initial negative gap to a positive gap at the end of the phase, which can be considered consistent with the generally observed delay in labor market developments in the real economy. The year-on-year decrease in employment support (by $4.0 \%$ ) and the year-on-year increase in Brent oil prices (by $30.8 \%$ ) contributed to the shift of the estimated PC to the right compared to the previous phase of the first recession (see Graph 1).

In the following period - the second recession ( $2 Q 2012$ to $3 Q 2013)$ there was a return of the negative slope of the PC - statistically insignificant. The value of -0.14 is significantly 
lower than the values of the PC slope in the initial phase of the economic cycle. This result of the model estimate is in line with the sharp year-on-year increase in government employment support (by $105.6 \%$ ). For men it was -0.16 and for women the negative slope was 0.13 . The average NAIRU during the second recession was $6.64 \%$. By comparing the NAIRU with the actual unemployment rate, we obtained a negative unemployment gap in this period of an average of $+0.46 \mathrm{pp}$, which indicates the phase of the recession in the labor market. The shift in the estimated PC further to the left compared to the previous phase (see Graph 1) was mainly due to the year-on-year decline in Brent oil prices (by 1.0\%) and employment support (by 105.6\%).

In the last period - the third boom (4Q 2013 to $3 Q$ of 2016) there was a statistically significant negative PC slope, with even higher than in the initial analyzed period and only slightly lower than in the first recession (-0.38). The substitution has a weak intensity. For the male data, the mean statistically confirmed slope was -0.44 (moderate substitutability). For the female data, the significant negative slope was -0.32 (weak substitutability). The average NAIRU value in the third boom period was $5.50 \%$. After deducting the NAIRU estimate from the actual unemployment rate, we located a positive unemployment gap in this period of an average of $-0.10 \mathrm{pp}$, which indicates the phase of the boom in the labor market in accordance with data from the real economy. The shift of the estimated PC further to the left compared to the previous phase (see Graph 1) was mainly due to a significant year-onyear increase in employment support (by $40.7 \%$ ), but also to a year-on-year decrease in the price of Brent crude oil (by 23.0\%).

\section{Graph 1}

Development of PC in individual phases of the economic cycle and NAIRU (y-axis household consumption deflator year-on-year change in percentage points, $y$-axis unemployment rate in\%)

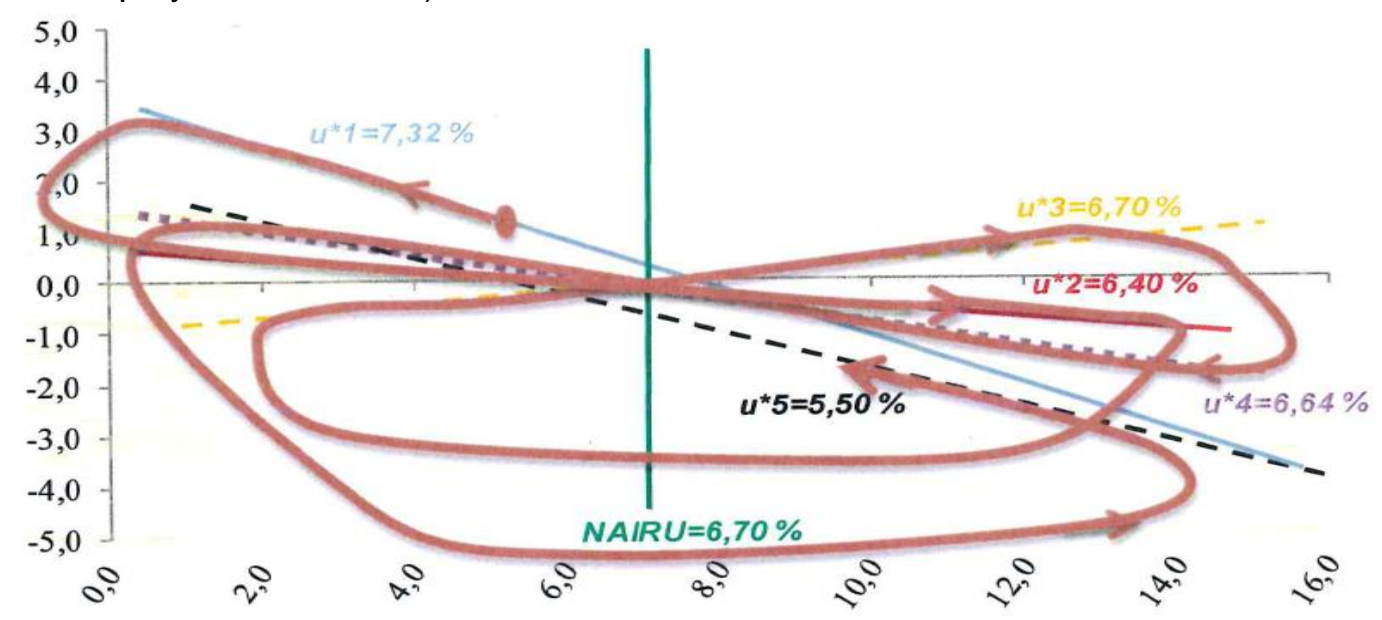

Source: Own calculation based on Eurostat and OECD data

\section{b. Analysis of the development of PC slope and NAIRU values in Poland}

The first boom (Q1 2001 to Q4 2008) was also in Poland typically characterized by a negative slope PC EUR 0.20, indicating a very weak intensity substitution. In the case of data for men, the statistically significant negative slope of the PC was 0.17 . For women, the average value was -0.24 . The slope of the PC averaged $-0.08(-0.08$ in men and -0.09 in women). The average value of NAIRU in the period of the first boom was $16.10 \%$. By comparing the NAIRU estimate with the actual unemployment rate, the unemployment gap in this period was positive at an average of $-0.2 \mathrm{pp}$, which is in line with the phase of the 
economic cycle. The location of the estimated PC (see Graph 2) was largely the result of a year-on-year increase in the price of Brent crude oil (by 17.8\%) and import prices (by 2.2\%).

In the following year - the first recession (Q1 2009 to Q4 2009) was located only a negative slope, which could not be statistically confirmed. An average negative slope of 0.11 also means a decrease in the intensity of substitution over the initial period. This result of the model estimate is in line with the sharp year-on-year increase in employment support by the government (by 118.4\%). In the case of data for men, the value was -0.12 . In the case of data for women, the average value of the negative slope was 0.10 . The average NAIRU during the first recession was $9.3 \%$. By comparing the NAIRU estimate with the actual unemployment rate, a positive unemployment gap of $-1.0 \mathrm{pp}$ was identified, which is in conflict with the phase of recession indicated by published GDP. The significant shift of the estimated PC to the left compared to the first phase of the boom (see Graph 2) was due, among other things, to the application of employment support measures, which increased by $118.4 \%$ year on year, and start-up incentives $(+18.0 \%)$. The year-on-year fall in Brent oil prices (by $36.7 \%$ ) also made a significant contribution.

In the next period - the second boom (1Q 2010 to $4 Q 2011)$, only a positive tendency was statistically confirmed in all combinations of both sexes. The average value of the slope was +0.07 in both genders. For the male data, the gradients ranged from 0.03 to 0.12 . Inclinations of PC from 0.02 to 0.14 were found in the female data. The average statistically confirmed NAIRU value in the second boom period was $9.20 \%$. After deducting the NAIRU estimate from the actual unemployment rate, we located a negative unemployment gap of $+0.60 \mathrm{pp}$ in this period, which indicates the phase of the labor market recession instead of the boom period, which results from real economy data. The discrepancy with the actual development cannot be explained by the delay of the labor market behind the real economy, as within this period the unemployment gap returns to the initial value $(+0.7 \mathrm{pp}$.) After a temporary reduction (+0.3 pp.). Due to the failure of the verification of model estimates, the data of the real economy must work with caution with the result and insert a statistically significant PC into the graph with caution. The slight shift in the estimated PC to the left compared to the previous phase of the first recession (see Graph 2) was due, among other things, to a yearon-year decline in import price inflation (by 2.9 pp) and an increase in start-ups (by 6.2 pp).

In the following period - the second recession (Q1 2012 to Q4 2013), only a negative PC slope was found, which indicated an acceleration of substitutability against the first recession and even against the initial boom. The average value of the statistically confirmed slope was -0.29 and PC can be evaluated as flat. For male data, the slope value was -0.29 . For the female data, the mean slope value was -0.28 . The average statistically unconfirmed negative slope was 0.11 , of which 0.12 was for men and 0.10 for women. The average NAIRU during the second recession was $9.30 \%$. Subtracting the statistically confirmed NAIRU estimate from the actual unemployment rate, a negative unemployment gap of $+1.00 \mathrm{pp}$ arose in this period, which corresponds to the phase of the economic cycle according to published GDP. The shift in the estimated PC slightly to the right compared to the previous phase (see Graph 2) was due, among other things, to a year-on-year decrease in the Start up application (by $17.9 \%$ ) and a year-on-year increase in import prices (by 2.0\%).

In the last period - the third boom (Q1 2014 to Q3 2016) only a negative PC slope was also found, however, in this phase of the economic cycle it was only a statistically unconfirmed substitution. This result of the econometric estimate is in line with only a minimal year-onyear increase in government start-ups (by 6.7\%). The average value of the PC slope was only -0.07 . For male data there was a very weak substitution with slope values in the range from 0.04 to 0.12 and for female data from 0.03 to 0.12 . The average NAIRU value in the 
third boom period was $8.00 \%$. By comparing the NAIRU estimate with the actual unemployment rate, a positive unemployment gap of $-0.20 \mathrm{pp}$ was averaged in this period, which is in line with the boom phase indicated by published GDP in s.c. The shift in the estimated PC sharply to the left compared to all previous phases of the economic cycle (see Graph 2) was mainly due to a year-on-year decline in import prices (by $1.5 \%$ ), Brent crude oil (by $24.5 \%$ ) and year-on-year growth in employment support (23.7\%) and Start-up (by $6.7 \%$ ).

\section{Graph 2}

Development of PC in individual phases of the economic cycle and NAIRU (y-axis household consumption deflator year-on-year change in percentage points, $y$-axis unemployment rate in\%)

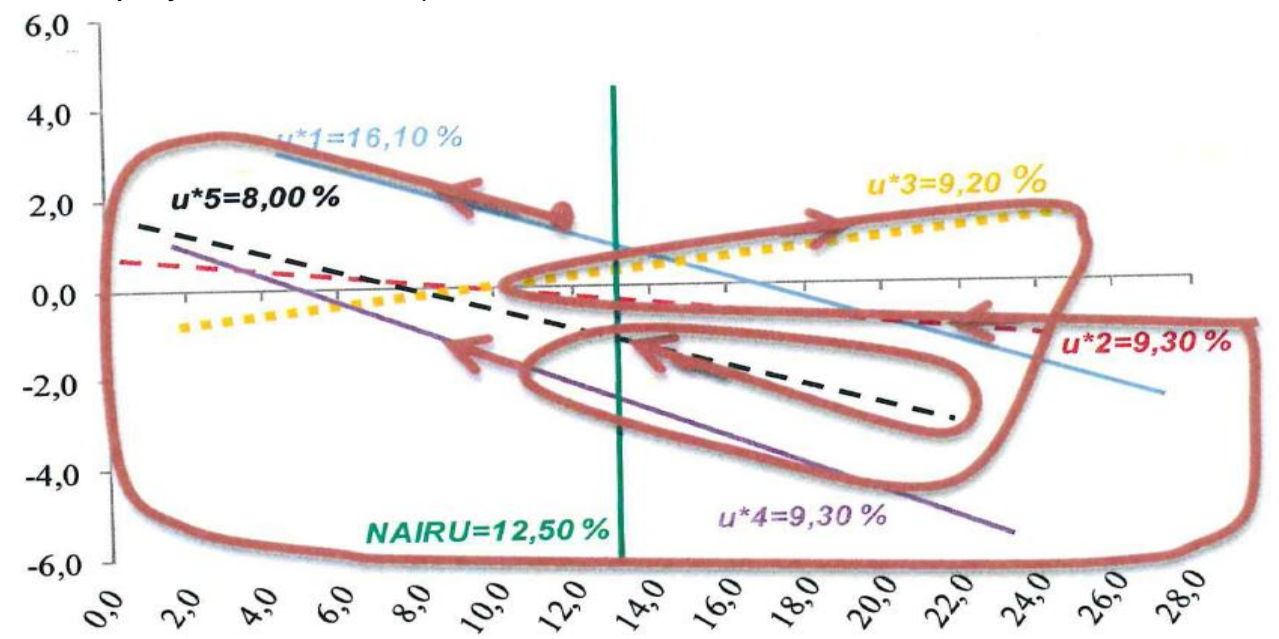

Source: Own calculation based on Eurostat and OECD data

\section{Conclusion}

The resulting average value of the negative slope of the PC for the entire observed period, which in the Czech Republic also contains a statistically confirmed positive slope of the PC during the second boom, is -0.19 . In Poland, the average value of the negative slope of the $\mathrm{PC}$ in the amount of -0.09 also contains a statistically significant positive slope in the period of the second boom. In both countries, the result indicates a very weak intensity of substitutability of the household consumption deflator by unemployment. The result of the analysis for the Czech Republic and Poland is in line with the conclusion of Gordon (2013), who rejects the widely presented failure of the PC and its inclusion in the intellectual history of economic history. For male data in both countries, the average value of the inclination (0.21 and -0.09 , respectively) was supported mainly by the age groups $25-54$ years and 55-64 years with upper secondary education. In the Czech Republic it was a tendency of -0.59 with medium-strong substitution, resp. -0.31 with weak substitution. In Poland, there was a very weak substitution $(-0.15$ and -0.13$)$. For the female data, the mean value was -0.16 and 0.08 , respectively. In the Czech Republic, the same age groups and the same level of education as men $(-0.31$ and -0.29 , respectively) played a decisive role in quantifying this weak substitution. In Poland, it was mainly the age group 55-64 years, which showed very weak substitution $(-0.13$ and -0.14 , respectively).

In the Czech Republic, the average value of the long-term NAIRU for the entire period under review, after the inclusion of an excusable discrepancy with the data the time of the first recession and the second boom, was $6.7 \%$. In Poland, this NAIRU was $12.50 \%$ after explaining the discrepancy with the data in the first recession and the unexplained failure of verification in the second economic boom phase. 
The determination of the estimated long-term NAIRU in the whole period was the result of opposite tendencies in the development of the labor market as well as outside it in the Czech Republic and Poland. The significant year-on-year growth of Start up (by $12.4 \%$ and $23.3 \%$, respectively) and employment support (by $6.6 \%$ and $17.2 \%$, respectively) was the main factor in the decline in the NAIRU. In the Czech Republic, there was also a year-on-year decrease in the price of Brent crude oil (by $4.5 \%$ ) and import prices (by $0.6 \%$ ). The growth of the NAIRU in the Czech Republic caused a year-on-year increase in the minimum wage (by $5.5 \%)$. In Poland, in addition to the minimum wage $(+6.6 \%)$, these were also the prices of Brent crude oil and import prices $(+6.6 \%$ and $+2.3 \%)$.

The point of intersection of the short-term NAIRU with the long-term NAIRU during the first boom period in the Czech Republic and Poland corresponds to inflation expectations (0.5 and $1.2 \%$ ). In the subsequent period of the first recession, agents in both countries expected the same deflation $(0.1$ and $0.2 \%$, respectively). During the second boom, inflation expectations in both countries were equally strong (+ $0.2 \%)$. While in the Czech Republic the subsequent period of the second recession was characterized by moderate deflationary expectations $(-0.1 \%)$, in Poland it was a robust deflationary expectations $(-2.0 \%)$. In the final phase of the third boom, deflationary expectations rose in the Czech Republic and fell in Poland (0.8 and $1.0 \%$, respectively).

\section{References}

AKERLOF, G. A.; DICKENS, W. T.; PERRY, G. L. 1996. The Macroeconomics of Low Inflation. Brookings Papers on Economic Aktivity. Brookings Institution.

ANDRLE, M.; BRU゚HA, J.; SOLMAZ, S. 2013. Inflation and Output Comovement in the Euro Area: Love at Second Sight? Working paper Series 7. Česká národní banka.

ATTWOOD, T. 1816. The Remedy; or, Thoughts on the Present Distresses. Second edition, with additions. London.

BAILY, N. M.; TOBIN, J.; HOLT, CH.; WACHTER, M.; TOBIN, J.; JUSTER, T.; FRIEDMAN, B.; PERRY, G.; HALL, R.; OKUN, A.; FELDSTEIN, M.; DUESENBERRY, J.; GORDON, J. R. 1977. Macroeconomic Effects of Selective Public Employment and Wage Subsidies. Brookings Papers on Economic Activity, Vol. 1977, No. 2 (1977), pp. 511-544, Brookings Institution Press.

BALL, L.; MOFFITT, R. 2001. Productivity growth and the Phillips curve [Working paper series]. National Bureau of Economic Research.

BAXA, J.; PLAŠIL, M.; VAŠÍČEK, B. 2013. Inflation and the Steeplechase Between Economic Activity Variables. Working paper Series 15. Česká národní banka.

BROWN, A. J. 1955. The Great Inflation, 1939-1951. London: Oxford University Press.

COHEN, S. M. 1969. The Direct Effects of Federal Manpower Programs in Reducing Unemployment. University of Wisconsin Press, The Journal of Human Resources, Vol. 4, No. 4, pp. 491-507.

COIBION, O.; GORODNICHENKO, Y. 2015. Is the Phillips Curve Alive and Well after All? Inflation Expectations and the Missing Disinflation. American Economic Journal: Macroeconomics 2015, 7(1), 197-232.

EUROSTAT. 2017. Data used in analysis.

EVIEWS. 2013. EViews Version 7.2 Help Topics.

FABIANI, S.; MESTRE, R. 2001. A system approach for measuring the euro area NAIRU. ECB.

FISHER, I. 1926. „A Statistical Relation between Unemployment and Price Changes.” International Labour Review 13. Reprinted as "I Discovered the Phillips Curve." Journal of Political Economy 81 (March/April 1973). 
FRIEDMAN, M. 1968. The Role of Monetary policy. The American Economic Review.

GLOBAL ECONOMIC OUTLOOK. 2017. http://www.oecd.org/economy/outlook/.

GORDON, R. J. 2013. The Phillips Curve is alive and well: Inflation and the NAIRU During the Slow Recovery. National Bureau of Economic Research. Cambridge. Working Paper 19390.

GORDON, R. J. 1996. Problems in the Measurement and Performance of Service-sector Productivity in the United States. National Bureau of Economic Research, March 1996.

HUME, D. 1752. Of Money. Political Discourses by David Hume. Presented by the Worshipful Company of Goldsmiths, 1903.

HUMPHREY, T. M. September/October 1985. The early History of the PHILLIPS CURVE. Economic Review. Federal Reserve Bank of Richmond.

KATZ, F.L.; KRUEGER, B.A.; BURTLESS,G.; DICKENS, T. W.1999. The High-Pressure U.S. Labor Market of the 1990s. Brookings Papers on Economic Activity, Vol. 1999, No. 1 (1999), pp. 1-87.

KLEIN, L. R.; GOLDBERGER, A. S. 1955. An Econometric Model of the United States, 1929-1952. Amsterdam: North-Holland Publishing Company.

MA, J. 2014. The Modern Phillips Curve Revisited. Modern Economy, 5, 188-200.

MARJANOVIC, G.; MAKSIMOVIC, L.; STANISIC, N. 2015. Hysteresis and the NAIRU: The Case of Countries in Transition. Prague Economic Papers, DOI: 10.18267/j.pep.526.

MCADAM, P.; MCMORROW, K. 1999. The NAIRU Concept - Measurement uncertainties, hysteresis and economic policy role.

MILL, S. J. 1833. „The Currency Juggle“. Taitś Edinburg Magazine (1833). Reprinted in Vol. I of his Dissertations and Discussions. Boston: 1865.

PHELPS, E. S. 1967. Phillips Curves, Expectations of Inflation and Optimal Unemployment Over Time. Economica.

PHILLIPS, A. W. 1958. The relationship between unemployment and the rate of change of money wages in the United Kingdom 1861-1957. Economica.

REITZ, S.; SLOPEK, D. U. 2013. Fixing the Phillips Curve: The Case of Downward Nominal Wage Rigidity in the US. Internal Journal of Finance and Economics. Int. J. Fin. Econ. 19, 122-131 (2014).

RUSTICELLI, E. 2014. Rescuing the Phillips curve Making use of long-term unemployment in the measurement of the NAIRU. OECD Journal: Economic Studies. Vol. 2014/1.

SAMUELSON, P. A.; SOLOW, R. M. May 1960. Analytical aspects of Anti-inflation Policy. American Economic Association.

SEKHON, J. S. 1999. Estimation of the Natural Rate of Unemployment: 1955:01-1997:12. Harvard University, Berkeley.

THORNTON, H. 1802. An Enquiry into the Nature and Effects of the Paper Credit of Great Britain. Edited with an introduction by F. A. von Hayek. New York Rinehart and Company, Inc. 1939.

TINBERGEN, J. 1959. „An Economic Policy for 1936.” Reprinted in his Selected Papers. Edited by L. H. Klaassen, L. M. Koyck, and H. J. Witteveen. Amsterdam: North-Holland Publishing Company.

TINBERGEN, J. 1951. Business Cycles in the United Kingdom, 1870-1914. Amsterdam: NorthHolland Publishing Company.

TOBIN, J. 1997. Supply Constraints on Employment and Output: NAIRU versus Natural Rate. Cowles Foundation Paper 1150. Yale University, New Haven. 
WALLICH, C.H. 1978. Stabilization Goals: Balancing Inflation and Unemployment. The American Economic Review, Vol. 68, No. 2, Papers and Proceedings of the Ninetieth Annual Meeting of the American Economic Association, pp. 159-164

WATSON, W. M. 2014. What's Natural? Key Macroeconomic Parameters after the Great Recession Inflation Persistence, the NAIRU, and the Great Recession. American Economic Review: Papers \& Proceedings 201, 104(5), 31-364. 